\title{
Variations in exercise ventilation in hypoxia will affect oxygen uptake
}

\author{
J.A. LOEPPKY ${ }^{1,2^{*}}$, R.M. SALGADO ${ }^{3}$, A.C. SHEARD ${ }^{4}$, \\ D.O. KUETHE ${ }^{5}$ and C.M. MERMIER ${ }^{6}$
}

${ }^{1}$ Department of Health, Exercise and Sports Sciences, University of New Mexico, Albuquerque, NM 87131, Canada

${ }^{2}$ Research Section, VA Medical Center, Albuquerque, NM 87108, Canada

${ }^{3}$ United States Army Research, Institute of Environmental Medicine, Thermal and Mountain Medicine Division, Natick, MA 01760, USA

${ }^{4}$ School of Kinesiology and Nutritional Science, California State University, Los Angeles, CA 90032, USA

${ }^{5}$ New Mexico Resonance, Albuquerque, NM 87106, Canada

${ }^{6}$ Department of Health, Exercise and Sports Sciences, University of New Mexico, Albuquerque, NM 87131, Canada

Received: February 13, 2020 • Accepted: July 3, 2020

Published online: October 3, 2020

(C) 2020 Akadémiai Kiadó, Budapest

\section{ABSTRACT}

Reports of $\mathrm{VO}_{2}$ response differences between normoxia and hypoxia during incremental exercise do not agree. In this study $\mathrm{VO}_{2}$ and $V_{E}$ were obtained from 15-s averages at identical work rates during continuous incremental cycle exercise in 8 subjects under ambient pressure $(633 \mathrm{mmHg} \approx 1,600 \mathrm{~m})$ and during duplicate tests in acute hypobaric hypoxia $\left(455 \mathrm{mmHg} \approx 4,350 \mathrm{~m}\right.$ ), ranging from 49 to $100 \%$ of $\mathrm{VO}_{2}$ peak in hypoxia and $42-87 \%$ of $\mathrm{VO}_{2}$ peak in normoxia. The average $\mathrm{VO}_{2}$ was $96 \mathrm{~mL} / \mathrm{min}(619 \mathrm{~mL})$ lower at 455 $\mathrm{mmHg}$ (n.s. $P=0.15$ ) during ramp exercises. Individual response points were better described by polynomial than linear equations $(\mathrm{mL} / \mathrm{min} / \mathrm{W})$. The $V_{E}$ was greater in hypoxia, with marked individual variation in the differences which correlated significantly and directly with the $\mathrm{VO}_{2}$ difference between 455 $\mathrm{mmHg}$ and $633 \mathrm{mmHg}(P=0.002)$, likely related to work of breathing $\left(W_{b}\right)$. The greater $V_{E}$ at $455 \mathrm{mmHg}$ resulted from a greater breathing frequency. When a subject's hypoxic ventilatory response is high, the extra work of breathing reduces mechanical efficiency $(E)$. Mean $\Delta E$ calculated from individual linear slopes was 27.7 and $30.3 \%$ at 633 and $455 \mathrm{mmHg}$, respectively (n.s.). Gross efficiency (GE) calculated from

* Corresponding author. Present address: 2725 7th Street South, Cranbrook, BC V1C4R8, Canada. Tel.: +1 (250) 489 4597; fax: +1 (250) 426 4440. E-mail: Loeppkyj@telus.net 
mean $\mathrm{VO}_{2}$ and work rate and correcting for $W_{b}$ from a $V_{E}-\mathrm{VO}_{2}$ relationship reported previously, gave corresponding values of 20.6 and $21.8(P=0.05)$. Individual variation in $V_{E}$ among individuals overshadows average trends, as also apparent from other reports comparing hypoxia and normoxia during progressive exercise and must be considered in such studies.

\section{KEYWORDS}

altitude acclimatization, hypobaric hypoxia, incremental exercise, mechanical efficiency, normobaric hypoxia, work of breathing

\section{INTRODUCTION}

Sophisticated techniques have been employed to quantify the direct relationship between exercise ventilation $\left(V_{E}\right)$ and $\mathrm{VO}_{2}$, suggesting that the work of breathing $\left(W_{b}\right)$ should be taken into account when $\mathrm{VO}_{2}$ response is the dependent variable $(1,2)$. This has been rarely considered when comparing exercise $\mathrm{VO}_{2}$ responses in normoxia and hypoxia in many situations and environments.

Studies comparing the amount of oxygen consumed in response to incremental or stepwise exercise between normoxia and hypobaric have received considerable attention by exercise physiologists. Inequality in the $\mathrm{VO}_{2}$ responses over the same work rate range has been attributed to differences in anaerobic metabolism (3-5), time lags in the rise time of $\mathrm{VO}_{2}(6$, 7), mechanical efficiency (8), and $\mathrm{O}_{2}$ stores (9). The $\mathrm{VO}_{2}$ response characteristics have also been used to assess changes with acclimatization to hypoxia and exercise training, with dissimilar results $(10,11)$. Investigators often assume a linear relationship between $\mathrm{VO}_{2}$ and work rate (slope: $\mathrm{mL} / \mathrm{min} / \mathrm{W}$ ) in these studies, often to calculate and compare delta efficiency $(\Delta E)$. However, the average $\mathrm{VO}_{2}$ or total $\mathrm{O}_{2}$ consumed during incremental exercise can be obtained without the assumption of linearity to estimate gross efficiency (GE). A few reports have indicated that $\mathrm{VO}_{2}$ is lower during incremental exercise in hypoxia over the same power output $(5,12,13)$, suggesting increased mechanical efficiency, but some disagree (14). Inspections of averaged data from many studies where $\mathrm{VO}_{2}$-work rate relationships during exercise in hypobaric hypoxia and normoxia are available favor a lower $\mathrm{VO}_{2}$ and lower slope in hypoxia than normoxia (15-19).

Some studies have reported that the mechanical efficiency of exercise is reduced in acute hypobaric hypoxia $(8,20)$ or increased when breathing hypoxic gas mixtures $(5)$ relative to lower equivalent altitudes. Findings are not consistent and discrepancies may be due to variations in exercise testing protocols, gas exchange measuring devices, differences in ventilatory responses and definitions of mechanical efficiency.

This study compares the total oxygen consumed in hypobaric hypoxia (455 $\mathrm{mmHg}$ ) and normoxia (ambient: $633 \mathrm{mmHg}$ ) during incremental exercise in the same subjects over identical work rates from $\approx 46$ to $94 \%$ of $\mathrm{VO}_{2}$ peak without assuming slope linearity. The focus is on the effect that variability among subjects in the hypoxic ventilatory response might have on the difference of the $\mathrm{VO}_{2}$ response between normoxia and hypoxia.

Substantial variation in individuals' hypoxic ventilatory drive during exercise will affect the quantification of differences in pulmonary gas exchange between normoxia and hypoxia. This 
must be taken into consideration in studies of mechanical efficiency, evaluation of altitude acclimatization, and any exercise studies that involve hypoxia.

\section{METHODS}

These data were obtained during a research study previously reported with a different focus (2123). Eight male volunteers were cyclists and runners consistently performing an average of $6 \mathrm{hr} /$ wk of moderate and $2-3 \mathrm{hr} / \mathrm{wk}$ of vigorous exercise during the year prior to, and during the study. Means $\pm \mathrm{SD}$ for $\mathrm{VO}_{2}$ peak, age and weight were $55 \pm 5 \mathrm{~mL} / \mathrm{min} / \mathrm{kg}, 28 \pm 6 \mathrm{yr}$ and $75.4 \pm$ $8.4 \mathrm{~kg}$, respectively. All subjects resided between 1,500 and 1,600 $\mathrm{m}$ for at least 6 months before the study and during data collection. Written informed consent was obtained, as approved by the Human Research Review Committee at the University of New Mexico.

Each subject completed two incremental $\mathrm{VO}_{2}$ peak tests. One test took place under ambient conditions at $633 \pm 3 \mathrm{mmHg}(1,600 \mathrm{~m})$ and one following acute exposure to reduced pressure in a decompression chamber at $455 \pm 1 \mathrm{mmHg}$, equivalent to $4,350 \mathrm{~m}$ according to the equation of West (24). All subjects first completed the test at $633 \mathrm{mmHg}$ with hypobaric chamber doors open, and 6-9 days later performed the test at $455 \mathrm{mmHg}$. Subjects were tested at the same time of day at both pressures and refrained from strenuous exercise, caffeine, and alcohol for $24 \mathrm{hr}$ prior to testing. The average ambient temperature for all tests was $22 \pm 2{ }^{\circ} \mathrm{C}$. For tests at 455 $\mathrm{mmHg}$ the "ascent" rate was $20 \mathrm{mmHg} / \mathrm{min}$; subjects then rested approximately $30 \mathrm{~min}$ prior to initiating exercise.

The $\mathrm{VO}_{2}$ peak tests were performed on an electronically-braked cycle ergometer (Velotron DynaFit Pro, RacerMate, Spearfish, SD). Gas exchange was continuously measured breath-bybreath with a metabolic cart (ParvoMedics True One 2400, Sandy, UT). Heart rate (HR) was continuously monitored via telemetry (Polar Electro, model FS1, Woodbury, NY), while $\mathrm{O}_{2}$ saturation $\left(\mathrm{SpO}_{2}\right)$ was measured by finger pulse oximeter $\left(\mathrm{GO}_{2}\right.$ Pulse Oximeter, Philips Respironics, Andover, MA). Cycling at each subject's preferred cadence began at $70 \mathrm{~W}$ for the first minute and the work rate then increased $35 \mathrm{~W}$ every minute until volitional fatigue or inability to maintain the work rate. The average exercise time to reach $\mathrm{VO}_{2}$ peak was $9.5 \pm 1.4$ min at $633 \mathrm{mmHg}$ and $8.5 \pm 1.5 \mathrm{~min}$ at $455 \mathrm{mmHg}$. The average of $\mathrm{VO}_{2}$ and associated ventilatory measurements over 15-s intervals from 33 to $100 \%$ of peak work rate were recorded. Each 35-W work rate increment was divided into four quarters to coincide with the 15-s measurement intervals. The average number of recorded points for the 16 tests was 22 (range: 16-26). The measured values for the tests at 633 and $455 \mathrm{mmHg}$ were then superimposed and compared at identical work rates. The analyzed points at $455 \mathrm{mmHg}$ included those between 49 and $100 \%$ of $\mathrm{VO}_{2}$ peak and at $633 \mathrm{mmHg}$ those between 42 and $87 \%$ of $\mathrm{VO}_{2}$ peak because of the $15 \%$ average reduction of $\mathrm{VO}_{2}$ peak by all subjects at $455 \mathrm{mmHg}$.

\section{Calculations and statistics}

The average $\mathrm{VO}_{2}, V_{E}$, and other gas exchange measurements within the work rate range for each subject was obtained by summing all values within the range and dividing by the number of points. These averages for each of the 8 subjects were compared at 633 and $455 \mathrm{mmHg}$ by paired $t$-test. As an example, the $\mathrm{VO}_{2}$ values for one subject are shown in Fig. $1 \mathrm{~A}$ and the 
corresponding $V_{E}$ values in Fig. 1B. The $\mathrm{VO}_{2}$ curves shown in Fig. $1 \mathrm{~A}$ are those obtained by a 2nd order polynomial equation $\left(\mathrm{VO}_{2}=A+B W+C W^{2}\right)$ because retrospectively the integrated value of this equation divided by the work rate range closely approximated the averaged values, as the mean $\pm \mathrm{SD}$ of the absolute differences for $\mathrm{VO}_{2}$ for the 16 curves was $2.6 \pm 1.6 \mathrm{~mL} / \mathrm{min}$. The $\mathrm{O}_{2}$ difference in $\mathrm{mL}$ between 455 and $633 \mathrm{mmHg}$ is represented by the area denoted " $X$ " in Fig. 1A. This value of $-2,504 \mathrm{~mL}$ was obtained by multiplying the $\mathrm{VO}_{2}$ difference $(\mathrm{mL} / \mathrm{min})$ between 455 and $633 \mathrm{mmHg}$ by exercise time, i.e., [(2,606 - 3,042) 201W/35W/min)]. In Fig. 1A the positive coefficient of the $C$ term at $455 \mathrm{mmHg}$ indicates upward curvature and the small negative term in normoxia indicates downward curvature. The curves for $V_{E}$ were obtained by integration of the equation $\operatorname{Ln}\left(V_{E}\right)=A+B(W)$, as the mean \pm SD of these absolute differences from the averaged values was $0.6 \pm 0.3 \mathrm{~L} / \mathrm{min}$.

The $\mathrm{VO}_{2}$ vs. work rate slope is utilized to obtain $\Delta E(25,26)$, which is defined as, "the quotient of an amount of extra external mechanical power to the increase in metabolic power needed to overcome this amount of extra external mechanical power" (27). The $\mathrm{VO}_{2}$ values are converted to metabolic power with the constant of $0.00505 \mathrm{Kcal} / \mathrm{mL}$ of $\mathrm{O}_{2}$ at $\mathrm{RER}=1.00$ determined by Lusk (28). By multiplying $\mathrm{VO}_{2}(\mathrm{~mL} / \mathrm{min})$ by $4186 \mathrm{~J} / \mathrm{Kcal}$ and $\mathrm{min} 60 / \mathrm{s}$, the metabolic power in units of $\mathrm{J} / \mathrm{s}$ is obtained and $\Delta E$ in percent is: $100 \times[1 /(\mathrm{mL} / \mathrm{min} / \mathrm{W} \times$ $0.3523)$ ]. Thus, a decrease in slope indicates an increase in $\Delta E$. The $\Delta E$ is theoretically preferred to $\mathrm{GE}$ and net efficiency because of the difficulties in making baseline subtractions for $\mathrm{VO}_{2}$ at rest for the latter (29).

Data are reported as means $\pm \mathrm{SD}$. Paired $t$-tests were used to determine significance of differences between gas exchange measurements at 633 and $455 \mathrm{mmHg}$. The significance of the linear slope differences between pressures was computed by $t$-test, as described by Crow et al. (30). The significance of differences between linear and polynomial fits to the data was determined by $F$-tests. The correlation coefficient between variables was obtained by least squares linear regression. The level of significance was $P \leq 0.05$.

\section{RESULTS}

\section{Comparison of $\mathrm{VO}_{2}$ over equal work rate ranges at 455 and $633 \mathrm{mmHg}$}

The average of mixed expired $\mathrm{PCO}_{2}, \mathrm{PO}_{2}$, and $\mathrm{SpO}_{2}$ during the work rate range was significantly lower at $455 \mathrm{mmHg}$ compared to $633 \mathrm{mmHg}(24.4 \pm 3.1 \mathrm{vs} .31 .0 \pm 3.8 \mathrm{mmHg}$ and $60.9 \pm 3.6 \mathrm{vs}$. $90.4 \pm 3.8 \mathrm{mmHg})$ and $76.7 \pm 2.8$ vs. $93.1 \pm 2.4 \%$, respectively. The average respiratory exchange ratio (RER) and HR tended to be higher at $455 \mathrm{mmHg}(1.01 \pm 0.05$ vs. $0.95 \pm 0.05$ and $151 \pm 12$ vs. $141 \pm 15 \mathrm{~b} / \mathrm{min}), P=0.07$ for both.

The individual values for the 8 subjects for $\mathrm{O}_{2}$ and ventilatory components are shown in Table 1 as determined over the course of exercise as the average of the individual 15-s averages. The corresponding linear slope values are also indicated. At $455 \mathrm{mmHg}$ the average $\mathrm{O}_{2}$ uptake was $619 \mathrm{~mL}$ lower than at $633 \mathrm{mmHg}$ for 6 of the 8 subjects, but was not significant. These $\mathrm{O}_{2}$ differences were not significantly correlated with the differences in linear slopes $(P=0.30)$. However, $\mathrm{VO}_{2}$ at both pressures correlated significantly with $V_{E}$, and the work rate range, which is to be expected as the latter varied among subjects. The $V_{E}$ was better correlated with the work rate interval at $633 \mathrm{mmHg}(r=0.66, P=0.07)$ than at $455 \mathrm{mmHg}(r=0.29, P=0.49)$. The positive correlation between the differences between pressures in $\Delta \mathrm{VO}_{2}$ and $\Delta V_{E}$ was significant 


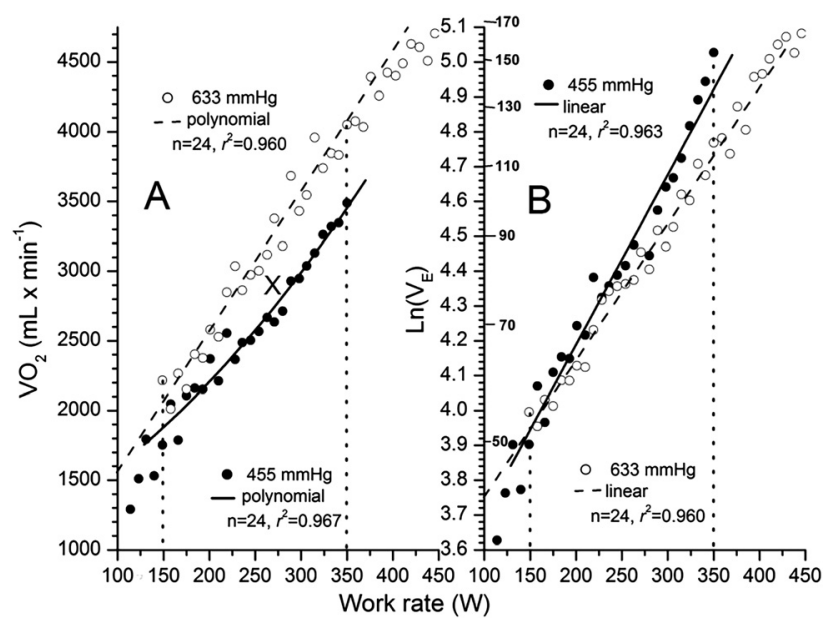

Fig. 1. $\mathrm{VO}_{2}$ and $V_{E}$ measurements for subject 1. Panel A: $\mathrm{VO}_{2}$ values are averaged over the same work rates from 149 to $350 \mathrm{~W}$ at 455 and $633 \mathrm{mmHg}$. At $633 \mathrm{mmHg}: \mathrm{VO}_{2}=3,042$ and at $455 \mathrm{~mm} \mathrm{Hg}: \mathrm{VO}_{2}=2,606$, for a difference of $-436 \mathrm{~mL} / \mathrm{min}$ or $-2,504 \mathrm{~mL}(-436 \times 201 / 35)$ denoted as area $X$ as indicated in Table 1 . The difference between the integration of the best fit polynomial equations at $633 \mathrm{mmHg}[Y=486+$ $\left.10.55(X)-0.0012\left(X^{2}\right)\right]$ and $455 \mathrm{mmHg}\left[Y=1,174+3.36(X)+0.0090\left(X^{2}\right)\right]$ between the dotted lines gives corresponding values of 3,043, 2,603, and $-440 \mathrm{~mL} / \mathrm{min}$. Panel B: At $633 \mathrm{mmHg}: V_{E}=78.9 \mathrm{~L} / \mathrm{min}$ and at 455: $V_{E}=88.0 \mathrm{~L} / \mathrm{min}$, for a difference of $9.1 \mathrm{~L} / \mathrm{min}$. Integration of the best fit linear equations of $\operatorname{Ln}\left(V_{E}\right)$ vs. $W$ at $633 \mathrm{mmHg}[Y=3.3619+0.0039(X)]$ and $455 \mathrm{mmHg}[Y=3.2126+0.0049(X)]$ between the dotted lines gives corresponding values of $78.7,87.4$, and $8.7 \mathrm{~L} / \mathrm{min}$

$(P=0.028)$. This is summarized in Fig. $2 \mathrm{~A}$ where percent changes for $\mathrm{VO}_{2}$ and $V_{E}$ are shown to take into account body size differences. Fig. $2 \mathrm{~B}$ shows that the breathing frequency difference $\left(\Delta f_{R}\right)$ also correlates highly with the $\Delta \mathrm{VO}_{2}$ difference and is the main contributor to the variability of $\Delta V_{E}$, indicated by a coefficient of variation of $60 \%$. This is also indicated by the $r$-value between $\Delta V_{E}$ vs. $\Delta f_{R}$ of $0.96(P<0.001)$. The difference in tidal volume $\left(\Delta V_{T}\right)$ also correlates significantly with $\Delta \mathrm{VO}_{2}$, but these changes are relatively small, as the increase in $V_{E}$ with hypoxia is $\approx 97 \%$ due to $f_{R}$ increases. The relationship between $\Delta V_{T}$ and $\Delta f_{R}$ was negative $(r=-0.52)$, but not significant, suggesting that increases in $\Delta f_{R}$ in hypoxia overrode possible increases in $V_{T}$. The correlations of $V_{E}, f_{R}$, and $V_{T}$ differences with linear slope differences in Table 1 were not significant, with $r$-values of $0.08,0.26$, and 0.44 , respectively.

The values for $\Delta E$, calculated from the slopes in Table 1 were $27.7 \pm 1.7 \%$ at $633 \mathrm{mmHg}$ and $30.3 \pm 3.8 \%$ at $455 \mathrm{mmHg}$, but not significantly different $(P=0.13)$. The $\Delta E$ differences were not significantly correlated with $\Delta \mathrm{VO}_{2}(r=-0.48, P=0.23)$. GE was calculated from $\mathrm{VO}_{2}$ as $100 \times \Delta W \times 1 /(\mathrm{mL} / \mathrm{min} \times 4186 \times 0.00505 / 60)$. These values are $19.5 \pm 1.4$ and $20.3 \pm 2.5 \%$ at 633 and $455 \mathrm{mmHg}$, respectively, and were also not different between normoxia and hypoxia $(P=0.23)$, but these differences correlated highly with $\Delta \mathrm{VO}_{2}(r=-0.98)$, as expected. The GE values are lower than for $\Delta E$ because $\mathrm{VO}_{2}$ now includes that at rest and work before $33 \%$ of the maximum work rate where recordings began. 
Table 1. Mean \pm 1.0 SD values between $=125 \pm 15$ and $312 \pm 43 \mathrm{~W}$ for 8 subjects at 633 and 455 mmHg pressure

\begin{tabular}{|c|c|c|c|c|c|c|c|c|c|c|c|c|c|c|c|}
\hline \multirow[b]{2}{*}{ Subject $(\Delta W)$} & \multicolumn{3}{|c|}{$\mathrm{VO}_{2}(\mathrm{~mL} / \mathrm{min})$} & \multicolumn{3}{|c|}{$\begin{array}{c}\text { Slope } \\
(\mathrm{mL} / \mathrm{min} / \mathrm{W})\end{array}$} & \multicolumn{3}{|c|}{$V_{E}(\mathrm{~L} / \min \mathrm{BTPS})$} & \multicolumn{3}{|c|}{$f_{R}(\mathrm{~b} / \mathrm{min})$} & \multicolumn{3}{|c|}{$V_{T}$ (L BTPS) } \\
\hline & 633 & 455 & $\Delta(\mathrm{mL})$ & 633 & 455 & $\Delta$ & 633 & 455 & $\Delta$ & 633 & 455 & $\Delta$ & 633 & 455 & $\Delta$ \\
\hline $1(201)$ & 3,042 & 2,606 & $-2,504$ & 9.97 & 7.85 & -2.12 & 78.9 & 88.0 & 9.1 & 25.8 & 26.7 & 0.9 & 3.06 & 3.30 & 0.24 \\
\hline $2(202)$ & 2,778 & 2,843 & 375 & 11.29 & 8.97 & -2.32 & 81.8 & 115.9 & 34.1 & 27.2 & 37.8 & 10.6 & 3.01 & 3.07 & 0.06 \\
\hline $3(131)$ & 2,128 & 2,424 & 1,108 & 10.21 & 10.90 & 0.70 & 57.8 & 108.7 & 50.9 & 24.0 & 45.7 & 21.7 & 2.41 & 2.38 & -0.03 \\
\hline $4(201)$ & 2,606 & 2,381 & $-1,292$ & 9.44 & 9.40 & -0.04 & 70.3 & 80.8 & 10.5 & 25.0 & 28.2 & 3.2 & 2.81 & 2.87 & 0.05 \\
\hline $5(219)$ & 3,000 & 2,848 & -951 & 10.41 & 8.32 & -2.09 & 84.5 & 110.8 & 26.3 & 27.4 & 34.3 & 6.9 & 3.08 & 3.23 & 0.15 \\
\hline $6(184)$ & 2,787 & 2,640 & -773 & 10.32 & 9.05 & -1.27 & 97.9 & 118.6 & 20.7 & 33.7 & 40.4 & 6.7 & 2.91 & 2.94 & 0.03 \\
\hline $7(210)$ & 3,092 & 2,976 & -696 & 11.01 & 10.63 & -0.38 & 73.9 & 110.9 & 37.0 & 26.6 & 37.1 & 10.5 & 2.78 & 2.99 & 0.21 \\
\hline $8(149)$ & 2,265 & 2,213 & -221 & 9.60 & 10.87 & 1.26 & 52.8 & 63.6 & 10.8 & 21.0 & 24.6 & 3.6 & 2.51 & 2.59 & 0.07 \\
\hline Mean & 2,712 & 2,616 & -619 & 10.28 & 9.50 & -0.78 & 74.7 & 99.7 & 24.9 & 26.3 & 34.4 & 8.0 & 2.82 & 2.92 & 0.10 \\
\hline SD & 358 & 265 & 1,087 & 0.64 & 1.18 & 1.37 & 14.6 & 19.8 & 15.0 & 3.6 & 7.3 & 6.5 & 0.25 & 0.31 & 0.09 \\
\hline$P$ diff. & & & 0.15 & & & 0.15 & & & 0.002 & & & 0.010 & & & 0.020 \\
\hline$r$ vs. $\Delta \mathrm{vO}_{2}$ & & & - & & & 0.42 & & & 0.76 & & & 0.84 & & & -0.74 \\
\hline Sign. of $r$ & & & - & & & 0.30 & & & 0.028 & & & 0.009 & & & 0.037 \\
\hline
\end{tabular}

$\Delta W$ : work rate range for each subject.

$\Delta(\mathrm{mL})$ is calculated as $\left(\mathrm{VO}_{2}\right.$ at $455-\mathrm{VO}_{2}$ at 633$) \times \mathrm{W} / 35 \mathrm{~W} / \mathrm{min}$.

Bold: $P<0.05$. 


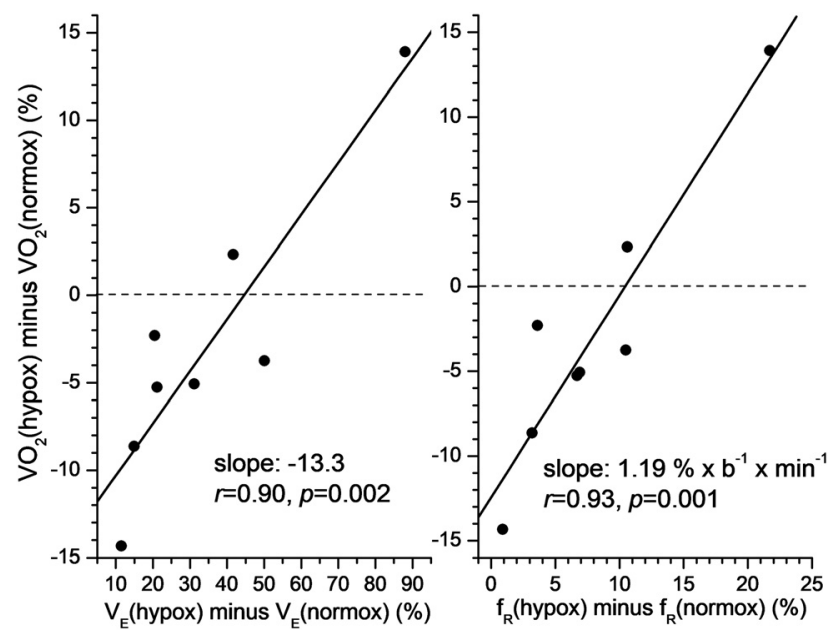

Fig. 2. Panel A: Significant relationship between percent change in $\mathrm{VO}_{2}$ and $V_{E}$ from $633 \mathrm{mmHg}$ to 455 mmHg in 8 subjects. Panel B: Significant relationship between increase in $\mathrm{f}_{\mathrm{R}}$ and percent change in $\mathrm{VO}_{2}$ from $633 \mathrm{mmHg}$ to $455 \mathrm{mmHg}$ in 8 subjects

\section{Comparison of combined $\mathrm{VO}_{2}$ vs. work rate measurements}

The 179 points for all subjects at both pressures, each a 15 -s average of $\mathrm{VO}_{2}$, are shown in Fig. 3, with the curves of the polynomial equations that describe the two sets of data points, with linear

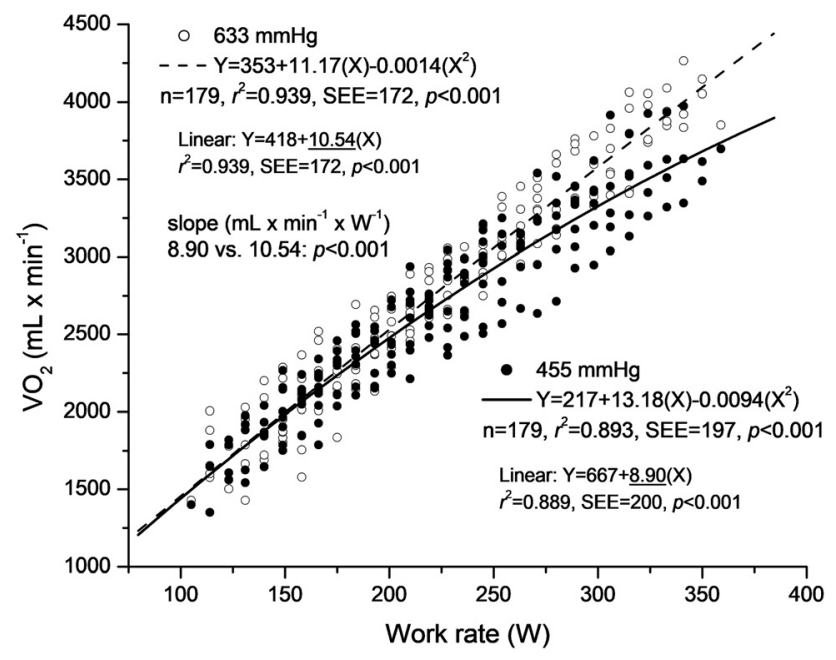

Fig. 3. Individual data points (179) for 8 subjects from $\approx 46$ to $94 \%$ of $\mathrm{VO}_{2}$ peak at 455 and $633 \mathrm{mmHg}$. The lines calculated by best fit polynomial and linear equations are indicated 


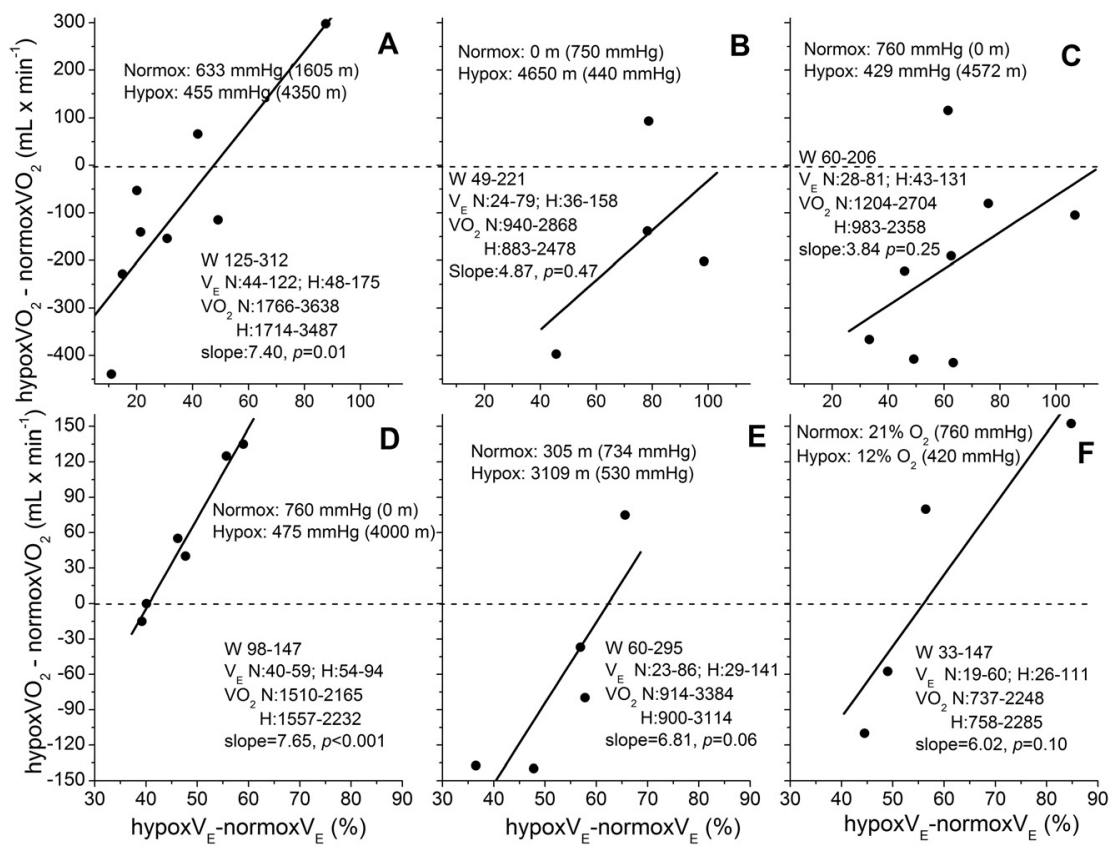

Fig. 4. Association of percent increases of $V_{E}$ in hypoxia over normoxia and corresponding $\mathrm{VO}_{2}$ difference during incremental exercise from individuals in 6 studies. Data for $V_{E}$ and $\mathrm{VO}_{2}$ for each study were analyzed as shown in Fig. $1 \mathrm{~A}$ and B. Panel A: this study, with continuous ramp cycling in hypobaric hypoxia. Panel B: from Pugh et al. (16), with continuous and discontinuous ramp cycling at altitude. Panel C: from Sutton et al. (18) and Reeves et al. (36) in OEII, with continuous and discontinuous ramp cycling in hypobaric hypoxia. Panel D: from Stenberg et al. (37), with discontinuous cycling in hypobaric hypoxia. Panel E: from Reeves et al. (17), with discontinuous treadmill running at altitude. Panel F: from Hughes et al. (38), with continuous cycling with hypoxic gas mixture. All relationships are positive, indicating an average increase of $6 \mathrm{~mL} / \mathrm{min}$ of $\mathrm{VO}_{2}$ above normoxia per one percent increase in $V_{E}$. The average increase in peak $V_{E}$ with hypoxia is $70 \%$; indicating that $W_{b}$ could have contributed $\approx 420 \mathrm{~mL} / \mathrm{min}$ to peak $\mathrm{VO}_{2}$ in hypoxia. The average minimum and maximum values for subjects in each study are noted for work rate $(W), V_{E}$ and $\mathrm{VO}_{2}$ in normoxia $(N)$ and hypoxia $(H)$, with linear slopes of regressions shown

equations also indicated in the legend. The best fit linear least squares regression slope at 455 $\mathrm{mmHg}\left(\mathrm{P}_{\mathrm{I}} \mathrm{O}_{2}=85 \mathrm{mmHg}\right)$ is 8.90 and is significantly lower $(P<0.001, t=5.27)$ than the 10.54 value at $633 \mathrm{mmHg}\left(\mathrm{P}_{\mathrm{I}} \mathrm{O}_{2}=123 \mathrm{mmHg}\right)$. The polynomial fits to the data points suggest downward curvature at both pressures, barely noticeable at $633 \mathrm{mmHg}$, but more apparent at $455 \mathrm{mmHg}$. However, an $F$-test comparing the variances of the linear vs. polynomial fit at 633 $\mathrm{mmHg}$ resulted in $P=0.51(F=0.995)$ and $P=0.42(F=1.032)$ at $455 \mathrm{mmHg}$. Thus, there is no evidence that the polynomial fit is statistically superior at either pressure for the grouped points. 


\section{DISCUSSION}

A large variation in individual's $V_{E}$ response to hypoxia has been previously reported and characterized (31). Undoubtedly the increased work of breathing $\left(W_{b}\right)$ contributes to the close correlation between differences in $V_{E}$ and $\mathrm{VO}_{2}$ noted in Fig. 2A. The $\mathrm{O}_{2}$ cost of breathing can amount to $10 \%$ or more of total $\mathrm{VO}_{2}$ during maximal exercise hyperpnea as the cost rises exponentially with work rate $(1,2)$. For example, subject 2 in Table 1 reached a maximal $V_{E}$ of $184 \mathrm{~L} / \mathrm{min}$ at $455 \mathrm{mmHg}$, compared to $85 \mathrm{~L} / \mathrm{min}$ at the same work rate at $633 \mathrm{mmHg}$. This difference in $V_{E}$ amounts to $\approx 322 \mathrm{~mL} / \mathrm{min}$ of $\mathrm{VO}_{2}$ according to the $W_{b}$ vs. $V_{E}$ relationship reported by Dominelli et al. (2), where $\mathrm{VO}_{2}=1.04+52.6 \mathrm{e}^{(V E / 84.3)}$. Any reduction in $W_{b}$ from reduced air density at $455 \mathrm{mmHg}$ is likely of minor influence because at $455 \mathrm{mmHg}$ the $V_{E}$ is higher and bronchoconstriction (32) and interstitial pulmonary edema (19) due to hypoxia probably contribute to $W_{b}$. The increased cost at $455 \mathrm{mmHg}$ is likely further enhanced by the higher $f_{R}$ which may be above the optimal frequency to minimize $W_{b}(33,34)$. The $W_{b}$ vs. $V_{E}$ relationship above would reduce the mean $\mathrm{VO}_{2}$ averages in Table 1 by 138 and $190 \mathrm{~L} / \mathrm{min}$ at 633 and $455 \mathrm{mmHg}$, respectively.

The $\mathrm{VO}_{2}$ values shown in Fig. 3 are the same below $\approx 175 \mathrm{~W}$. This is not surprising, as the slope has been reported to be similar in normoxia and hypoxia during steady state submaximal exercises at lower work rates at simulated altitude (22) and with hypoxic gas mixtures (12). Linear slopes of the curves in Fig. 3 are generally similar to the average curves during incremental exercise utilizing hypoxic gas mixtures previously reported $(13,35)$. However, the significant difference in linear slopes between 633 and $455 \mathrm{mmHg}$ in Fig. 3 is misleading as a general axiom because only 4 of the individual comparisons showed a significantly lower slope at $455 \mathrm{mmHg}$, with a higher slope at $633 \mathrm{mmHg}$ occurring in 2 of 8 subjects (n.s.), with essentially no difference in 2 subjects. A polynomial fit to the individual $\mathrm{VO}_{2}$ vs. work rate curves resulted in three positive values for the $C$ term at 633 and two at $455 \mathrm{mmHg}$ (upward curvature, presumably related to enhanced $W_{b}$ ) and 5 negatives values at 633 and 6 at $455 \mathrm{mmHg}$ (downward curvature, presumably related to anaerobic metabolism). To avoid the questionable assumption of linearity it seems more appropriate to utilize the individual differences in $\mathrm{VO}_{2}$ or $\mathrm{O}_{2}(\mathrm{~mL})$ in Table 1, rather than average curve slope shown in Fig. 3 to quantify differences between the normoxia and hypoxia.

The direct relationship between $V_{E}$ and $\mathrm{VO}_{2}$ shown in Fig. 2 is further supported by inspection of other reported studies indicated in Fig. 4, where individual subject's data were available for exercise in hypoxia and normoxia at the same work rates. These plots were constructed from five studies where four or more points were reported for individual subjects as referenced in the figure legend, using polynomial fits to $\mathrm{VO}_{2}$ and linear fits to $\operatorname{Ln}\left(V_{E}\right)$ vs. work rate as described in Fig. $1 \mathrm{~A}$ and $\mathrm{B}$. The change in $\mathrm{VO}_{2}$ from normoxia to hypoxia is clearly related to the percentage increase in $V_{E}$ (BTPS) by individuals in these diverse studies and subjects, even though statistical significance of the relationships is inconsistent, mainly due to the paucity of subjects.

\section{$\mathrm{VO}_{2}$ differences in normoxia and hypoxia during incremental exercise}

Table 1 and Fig. 4 indicate that $\Delta \mathrm{VO}_{2}$ vs. $\Delta$ work rate slope differences between normoxia and hypoxia are mainly attributable to individual variations in the $V_{E}$ response to hypoxic exercise. 
The $\mathrm{VO}_{2}$ differences measured over a range of continuous or discontinuous incremental work rates, rather than the calculated linear slope of $\mathrm{VO}_{2}$ seem more accurate for estimating differences between hypoxia and normoxia because minor deviations from linearity will have an appreciable effect on the result. For example, if differences in efficiency at 633 and $455 \mathrm{mmHg}$ are of interest, to avoid the assumption of linearity GE can be calculated from $\mathrm{VO}_{2}$ values in Table 1 for the 8 subjects and reducing $\mathrm{VO}_{2}$ for $V_{E}$ predicted according to the relationship by Dominelli et al. (2) above. These "non-respiratory" values are $20.6 \pm 1.6$ and $21.8 \pm 2.6)$ and are now significantly different between 633 and $455 \mathrm{mmHg}(P=0.05)$. The corresponding mean GE values for the five studies shown in Fig. 4 are $21.1 \pm 7.8$ and $22.7 \pm 8.9 \%$ in normoxia and hypoxia, respectively.

Some studies report that an increase in anaerobic metabolism contributes to the lower $\mathrm{VO}_{2}$ rise during exercise in hypoxia because as exercise in hypoxia progresses there is an increasing contribution by this energy source $(3-5,13)$. Unless compensated for by increased $W_{b}$, this would tend to lower the $\mathrm{VO}_{2}$ vs. work rate slope at higher work levels and result in a lower overall slope and higher $\Delta E$, especially at $455 \mathrm{mmHg}$, which was not the case here. The present study suggests that a greater increase in $V_{E}$ will offset a decrease in $\mathrm{VO}_{2}$ in hypoxia during exercise because there was no greater downward curvature in 8 individuals in hypoxia, as indicated by the $C$ term in the polynomials being only slightly more negative at $455 \mathrm{mmHg}$ than at $633 \mathrm{mmHg}(t=0.22, P=0.89)$.

A time lag in $\mathrm{VO}_{2}$ during a ramp exercise while breathing hypoxic gas has also been proposed $(4,6,7)$. These studies suggest that when the exercise stages during a continuous incremental exercise are too large the $\mathrm{VO}_{2}$ will lag behind in response to each load increment, thus reducing the slope. In partial contradiction to this, and the proposed greater anaerobic metabolism in hypoxia, is the observation that the post-exercise $\mathrm{O}_{2}$ consumption after peak intensity exercise is similar in hypoxia and normoxia (39-43).

Another consideration is that the $\mathrm{O}_{2}$ kinetics after the onset of exercise is affected by a reduction in body $\mathrm{O}_{2}$ stores (9). This is important when beginning exercise in hypoxia, as in the present study, where the initial phase of exercise will exhibit a lower $\mathrm{VO}_{2}$ at the mouth while body $\mathrm{O}_{2}$ stores are utilized. This early reduction in $\mathrm{VO}_{2}$ as blood $\mathrm{O}_{2}$ saturation decreases would increase the overall $\mathrm{VO}_{2}$ vs. work rate slope.

The lower density of the inspired air in hypobaric hypoxia in this study required $V_{E}(\mathrm{BTPS})$ to increase over the average work interval by $44 \%$ to supply the same $\mathrm{VO}_{2}$, but the average $V_{E}(\mathrm{STPD})$ increased only $33 \%$. This deficiency in $V_{E}(\mathrm{STPD})$ during acute hypoxia (presumably because of the acute nature of the hypoxia) may predispose the $\mathrm{VO}_{2}$ to be lower in hypoxia. The actual $V_{E}$ response to maintain the $\mathrm{O}_{2}$ requirements of the increasing workloads will vary with the sensitivity of the hypoxic chemoreceptors of the individual subjects. Ventilation during exercise increases at given work rates with altitude acclimatization $(44,45)$ and by affecting $\mathrm{VO}_{2}$ may also contribute to the inconsistent conclusions regarding the effect of acclimatization on efficiency estimates computed from the $\mathrm{VO}_{2}$-work rate slopes that was mentioned earlier.

In summary, these findings suggest that the variations in $V_{E}$ responses to exercise in hypobaric hypoxia may contribute substantially to the inconsistent results of previously reported comparisons of $\mathrm{VO}_{2}$ and computations of efficiency between normoxia and hypoxia during incremental exercise. These data suggest a slightly smaller $\mathrm{VO}_{2}$ for the same work rate at 455 vs. $633 \mathrm{mmHg}$, but certainly studies with more subjects are required for confirmation. The variation of $V_{E}$ responses to hypoxia of selected research subjects must be taken into account in studies 
comparing gas exchange at different levels of $\mathrm{PIO}_{2}$ and linear presumptions of $\mathrm{VO}_{2}$ vs. work rate relationships can be misleading.

\section{ACKNOWLEDGEMENTS}

We thank Dr. P.D. Wagner, University of California San Diego, for providing gas exchange data for the individual subjects in the OEII studies summarized in references 36 and 18. The opinions or assertions contained herein are the private views of the author(s) and are not to be construed as official or reflecting the views of the Army or the Department of Defence. Any citations of commercial organizations and trade names in this report do not constitute an official Department of the Army endorsement of approval of the products or services of these organizations. The authors declare that they have no conflicts of interest.

\section{REFERENCES}

1. Aaron EA, Seow KC, Johnson BD, Dempsey JA. Oxygen cost of exercise hyperpnea: implications for performance. J Appl Physiol 1992; 72: 1818-25.

2. Dominelli PB, Render JN, Molgat-Seon Y, Foster GE, Sheel AW. Precise mimicking of exercise hyperpnea to investigate the oxygen cost of breathing. Respir Physiol Neurobiol 2014; 201: 15-23.

3. Engelen M, Porszasz J, Riley M, Wasserman K, Maehara K, Barstow TJ. Effects of hypoxic hypoxia on $\mathrm{O}_{2}$ uptake and heart rate kinetics during heavy exercise. J Appl Physiol 1996; 81: 2500-8.

4. Lador F, Tam E, Adami A, Kenfack MA, Bringard A, Cautero M, et al. Cardiac output, $\mathrm{O}_{2}$ delivery and $\mathrm{VO}_{2}$ kinetics during step exercise in acute normobaric hypoxia. Respir Physiol Neurobiol 2013; 186: 206-13.

5. Prieur F, Benoit H, Busso T, Castells J, Denis C. Effect of endurance training on the $\mathrm{VO}_{2}$-work rate relationship in normoxia and hypoxia. Med Sci Sports Exerc 2005; 37: 664-9.

6. Hughson RL, Kowalchuk JM. Kinetics of oxygen uptake for submaximal exercise in hyperoxia, normoxia, and hypoxia. Can J Appl Physiol 1995; 20: 198-210.

7. Murphy PC, Cuervo LA, Hughson RL. A study of cardiorespiratory dynamics with step and ramp exercise tests in normoxia and hypoxia. Cardiovasc Res 1989; 23: 825-32.

8. Noordhof DA, Schoots T, Hoekert DH, de Koning JJ. Is gross efficiency lower at acute simulated altitude than at sea level? Int J Sports Physiol Perform 2013; 8: 319-22.

9. Di Prampero PE, Boutellier U, Pietsch P. Oxygen deficit and stores at onset of muscular exercise in humans. J Appl Physiol Respir Environ Exerc Physiol 1983; 55: 146-53.

10. Latshang TD, Turk AJ, Hess T, Schoch OD, Bosch MM, Barthelmes D, et al. Acclimatization improves submaximal exercise economy at $5533 \mathrm{~m}$. Scand J Med Sci Sports 2013; 23: 458-67.

11. Lundby C, Calbet JA, Sander M, van Hall G, Mazzeo RS, Stray-Gundersen J, et al. Exercise economy does not change after acclimatization to moderate to very high altitude. Scand J Med Sci Sports 2007; 17: 281-91.

12. Benoit H, Busso T, Prieur F, Castells J, Freyssenet D, Lacour JR, et al. Oxygen uptake during submaximal incremental and constant work load exercises in hypoxia. Int J Sports Med 1997; 18: 101-5.

13. Ibañez J, Rama R, Riera M, Prats MT, Palacios L. Severe hypoxia decreases oxygen uptake relative to intensity during submaximal graded exercise. Eur J Appl Physiol Occup Physiol 1993; 67: 7-13. 
14. Heubert RA, Quaresima V, Laffite LP, Koralsztein JP, Billat VL. Acute moderate hypoxia affects the oxygen desaturation and the performance but not the oxygen uptake response. Int J Sports Med 2005; 26: 542-51.

15. Bender PR, Groves BM, McCullough RE, McCullough RG, Huang SY, Hamilton AJ, et al. Oxygen transport to exercising leg in chronic hypoxia. J Appl Physiol 1988; 65: 2592-7.

16. Pugh LGCE, Gill MB, Lahiri S, Milledge JS, Ward MP, West JB. Muscular exercise at great altitudes. J Appl Physiol 1964; 19: 431-40.

17. Reeves JT, Grover RF, Cohn JE. Regulation of ventilation during exercise at 10,200 $\mathrm{ft}$ in athletes born at low altitude. J Appl Physiol 1967; 22: 546-54.

18. Sutton JR, Reeves JT, Wagner PD, Groves BM, Cymerman A, Malconian MK, et al. Operation Everest II: oxygen transport during exercise at extreme simulated altitude. J Appl Physiol 1988; 64: 1309-21.

19. Wagner PD, Gale GE, Moon RE, Torre-Bueno JR, Stolp BW, Saltzman HA. Pulmonary gas exchange in humans exercising at sea level and simulated altitude. J Appl Physiol 1986; 61: 260-70.

20. Clark SA, Bourdon PC, Schmidt W, Singh B, Cable G, Onus KJ, et al. The effect of acute simulated moderate altitude on power, performance and pacing strategies in well-trained cyclists. Eur J Appl Physiol 2007; 102: 45-55.

21. Loeppky JA, Sheard AC, Salgado RM, Mermier CM. $\mathrm{V}_{\mathrm{E}} \mathrm{STPD}$ as a measure of ventilatory acclimatization to hypobaric hypoxia. Physiol Int 2016; 103: 377-91.

22. Salgado RM, Sheard AC, Vaughan RA, Parker DL, Schneider SM, Kenefick RW, et al. Mitochondrial efficiency and exercise economy following heat stress: a potential role of uncoupling protein 3. Physiol Rep 2017; 5: e13054.

23. White AC, Salgado RM, Astorino TA, Loeppky JA, Schneider SM, McCormick JJ, et al. The effect of 10 days of heat acclimation on exercise performance in acute hypobaric hypoxia $(4350 \mathrm{~m})$. Temperature $2016 ; 3$ : $176-85$.

24. West JB. Prediction of barometric pressures at high altitude with the use of model atmospheres. J Appl Physiol 1996; 81: 1850-4.

25. Coyle EF, Sidossis LS, Horowitz JF, Beltz JD. Cycling efficiency is related to the percentage of type I muscle fibers. Med Sci Sports Exerc 1992; 24: 782-8.

26. Gaesser GA, Brooks GA. Muscular efficiency during steady-rate exercise: effects of speed and work rate. J Appl Physiol 1975; 38: 1132-9.

27. Bijker KE, De Groot G, Hollander AP. Delta efficiencies of running and cycling. Med Sci Sports Exerc 2001; 33: $1546-51$.

28. Lusk G. The elements of the science of nutrition. 3rd ed. Philadelphia, USA: W B Saunders; 1917 [Table, p. 61].

29. Stainsby WN, Gladden LB, Barclay JK, Wilson BA. Exercise efficiency: validity of base-line subtractions J Appl Physiol Respir Environ Exerc Physiol 1980; 48: 518-22.

30. Crow EL, Davis FA, Maxfield MW. Statistics manual. New York, NY: Dover; 1960. pp.160-1.

31. Eisele JH, Wuyam B, Savourey G, Eterradossi J, Bittel JH, Benchetrit G. Individuality of breathing patterns during hypoxia and exercise. J Appl Physiol 1992; 72: 2446-53.

32. Cruz JC. Mechanics of breathing in high altitude and sea level subjects. Respir Physiol 1973; 17: 146-61.

33. Bartlett RG, Jr., Brubach HF, Spect H. Oxygen cost of breathing. J Appl Physiol 1958; 12: 413-24.

34. Kennard CD, Martin BJ. Respiratory frequency and the oxygen cost of exercise. Eur J Appl Physiol Occup Physiol 1984; 52: 320-3.

35. Walsh ML, Banister EW. The influence of inspired oxygen on the oxygen uptake response to ramp exercise. Eur J Appl Physiol 1995; 72: 71-5. 
36. Reeves JT, Groves BM, Sutton JR, Wagner PD, Cymerman A, Malconian MK, et al. Operation Everest II: preservation of cardiac function at extreme altitude. J Appl Physiol 1987; 63: 531-9.

37. Stenberg J, Ekblom B, Messin R. Hemodynamic response to work at simulated altitude, 4,000 m. J Appl Physiol 1966; 21: 1589-94.

38. Hughes RL, Clode M, Edwards RH, Goodwin TJ, Jones NL. Effect of inspired $\mathrm{O}_{2}$ on cardiopulmonary and metabolic responses to exercise in man. J Appl Physiol 1968; 24: 336-47.

39. Asmussen E, Dobeln WV, Nielsen M. Blood lactate and oxygen debt after exhaustive work at different oxygen tensions. Acta Physiol Scand 1948; 15: 57-62.

40. Consolazio CF, Nelson RA, Matoush LR, Hansen JE. Energy metabolism at high altitude (3,475 m). J Appl Physiol 1966; 21: 1732-40.

41. Fellmann N, Bedu M, Spielvogel H, Falgairette G, Van Praagh E, Coudert J. Oxygen debt in submaximal and supramaximal exercise in children at high and low altitude. J Appl Physiol 1986; 60: 209-15.

42. Raynaud J, Martineaud JP, Bordachar J, Tillous MC, Durand J. Oxygen deficit and debt in submaximal exercise at sea level and high altitude. J Appl Physiol 1974; 37: 43-8.

43. Shephard RJ, Bouhlel E, Vandewalle H, Monod H. Anaerobic threshold, muscle volume and hypoxia. Eur J Appl Physiol Occup Physiol 1989; 58: 826-32.

44. Dejours P, Kellogg RH, Pace N. Regulation of respiration and heart rate response in exercise response to altitude acclimatization. J Appl Physiol 1963; 18: 10-8.

45. Hansen JE, Vogel JA, Stelter GP, Consolazio CF. Oxygen uptake in man during exhaustive work at sea level and high altitude. J Appl Physiol 1967; 23: 511-22. 